Prepared in cooperation with the New Jersey Department of Environmental Protection

\title{
Marine Geophysical Data Collected in a Shallow Back-Barrier Estuary, Barnegat Bay, New Jersey
}

Data Series 937

Version 1.1, September 2016 



\section{Marine Geophysical Data Collected in a Shallow Back-Barrier Estuary, Barnegat Bay, New Jersey}

By Brian D. Andrews, Jennifer L. Miselis, William W. Danforth, Barry J. Irwin, Charles R. Worley, Emile M. Bergeron, and Dann S. Blackwood

Prepared in cooperation with the

New Jersey Department of Environmental Protection

Data Series 937

Version 1.1, September 2016 


\title{
U.S. Department of the Interior SALLY JEWELL, Secretary
}

\section{U.S. Geological Survey Suzette M. Kimball, Director}

\author{
U.S. Geological Survey, Reston, Virginia \\ First release: 2015, online \\ Revised: September 2016 (ver. 1.1), online
}

For more information on the USGS —-the Federal source for science about the Earth, its natural and living resources, natural hazards, and the environment-visit http://www.usgs.gov/ or call 1-888-ASK-USGS.

For an overview of USGS information products, including maps, imagery, and publications, visit http://www.usgs.gov/pubprod/.

Any use of trade, firm, or product names is for descriptive purposes only and does not imply endorsement by the U.S. Government.

Although this information product, for the most part, is in the public domain, it also may contain copyrighted materials as noted in the text. Permission to reproduce copyrighted items must be secured from the copyright owner.

Suggested citation:

Andrews, B.D., Miselis, J.L., Danforth, W.W., Irwin, B.J., Worley, C.R., Bergeron, E.M., and Blackwood, D.S., 2016, Marine geophysical data collected in a shallow back-barrier estuary, Barnegat Bay, New Jersey (ver. 1.1, September 2016): U.S. Geological Survey Data Series 937, 15 p., http://dx.doi.org/10.3133/ds937.

ISSN 2327-638X (online) 


\section{Contents}

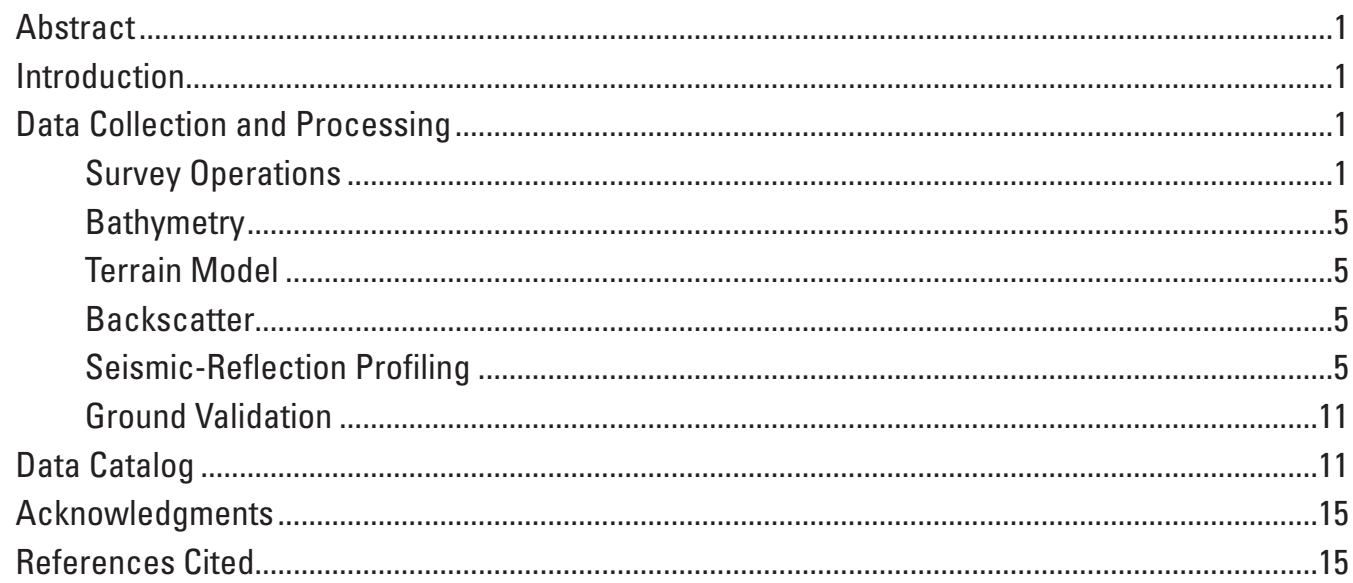

\section{Figures}

1. Map showing the watershed, regional bathymetry, and three inlets in Barnegat Bay, New Jersey.

2. Map showing areas covered by the four surveys conducted in Barnegat Bay, New Jersey, by the U.S. Geological Survey between 2011 and 2013.

3. Photograph of the research vessel (RV) Rafae/ showing the SWATHplus-H bathymetric sonar mounted on the bow.

4. Map showing bathymetric tracklines and tie lines collected in Barnegat Bay, New Jersey, by the U.S. Geological Survey between 2011 and 2013 ...

5. Process of converting bathymetric trackline data with gaps between adjacent lines to a continuous terrain model

6. Photographs of $A$, The Klein 3000 sidescan-sonar towfish used during survey 2011-041-FA and $B$, the EdgeTech 4200 sidescan sonar towfish used during surveys (2012-003-FA, 2013-014-FA, and 2013-030-FA).

7. Photograph of the EdgeTech 424 subbottom-profiling towfish and the davit used when deployed from the starboard side of the research vessel Rafael

8. Photograph of the SEABed Observation and Sampling System deployed from the research vessel (RV) Rafael.

9. Map showing the 186 target SEABed Observation and Sampling System sampling stations in areas surveyed by the U.S. Geological Survey in Barnegat Bay,

New Jersey, from 2011 to 2013

\section{Tables}

1. Details of the four geophysical surveys conducted by the U.S. Geological Survey in Barnegat Bay, New Jersey, between 2011 and 2013 .4

2. List of vector data published in this report in the shapefile directory ...............................14

3. List of bathymetric and backscatter data in the directories downloads/raster/ bathymetry/ and downloads/raster/backscatter/.

4. Bottom photographs and seismic profile images in the directories downloads/ hyperlink_images/bottom_photos/ and downloads/hyperlink_images/ seismic_profiles/.... 


\section{Conversion Factors}

International System of Units to Inch/Pound

\begin{tabular}{lll}
\hline \multicolumn{1}{c}{ Multiply } & By & \multicolumn{1}{c}{ To obtain } \\
\hline meter $(\mathrm{m})$ & Length & foot $(\mathrm{ft})$ \\
kilometer $(\mathrm{km})$ & 3.281 & mile $(\mathrm{mi})$ \\
\hline & 0.6214 & \\
\hline square kilometer $\left(\mathrm{km}^{2}\right)$ & Area & square mile $\left(\mathrm{mi}^{2}\right)$ \\
\hline & 0.3861 & \\
\hline meter per second $(\mathrm{m} / \mathrm{s})$ & Rate & foot per second $(\mathrm{ft} / \mathrm{s})$ \\
\hline
\end{tabular}

\section{Datum}

Vertical coordinate information is referenced to the North American Vertical Datum of 1988 (NAVD 88).

Horizontal coordinate information is referenced to the World Geodetic System of 1984 (WGS 84). Elevation, as used in this report, refers to distance above the vertical datum.

\section{Supplemental Information}

The frequency of multibeam bathymetry is measured in kilohertz $(\mathrm{kHz}), 1,000$ periods per second.

\section{Abbreviations}

JPEG

NJDEP

NOAA

PNG

RV

SEABOSS

TIN

USGS
Joint Photographic Experts Group

New Jersey Department of Environmental Protection

National Oceanic and Atmospheric Administration

Portable Network Graphics

research vessel

SEABed Observation and Sampling System

Triangulated Irregular Network

U.S. Geological Survey 


\title{
Marine Geophysical Data Collected in a Shallow Back- Barrier Estuary, Barnegat Bay, New Jersey
}

\author{
By Brian D. Andrews, Jennifer L. Miselis, William W. Danforth, Barry J. Irwin, Charles R. Worley, \\ Emile M. Bergeron, and Dann S. Blackwood
}

\section{Abstract}

In 2011, the U.S. Geological Survey, in cooperation with the New Jersey Department of Environmental Protection, began a multidisciplinary research project to better understand the water quality in Barnegat Bay, New Jersey. This back-barrier estuary is experiencing degraded water quality, algal blooms, loss of seagrass, and increases in oxygen stress, macroalgae, stinging nettles, and brown tide. The spatial scale of the estuary and the scope of challenges within it necessitate a multidisciplinary approach that includes establishing the regional geology and the estuary's physical characteristics and modeling how the estuary's morphology interacts to affect its water quality. This report presents the data collected during this project for use in understanding the morphology and the distribution of sea-floor and sub-sea-floor sediments within Barnegat Bay, describes the methods used to collect and process those data, and includes links to the final processed datasets. These data can be used by scientists to understand the links between geomorphology, geologic framework, sediment transport, and estuarine water quality and circulation.

\section{Introduction}

The Barnegat Bay estuary is a shallow back-barrier estuary along the coast of New Jersey, encompassing both Barnegat Bay and Little Egg Harbor, that is bounded on the west by the mainland and to the east by two barrier islands (fig. 1). The estuary covers 337 square kilometers $\left(\mathrm{km}^{2}\right)$ and is much longer (about 70 kilometers [km] from Point Pleasant Canal in the north to Little Egg Harbor in the south) than it is wide (about $7 \mathrm{~km}$ ). Historical soundings indicated that the estuary had a mean depth of 1.3 meters $(\mathrm{m})$ and an extensive system of shallow shoals (fig. 1; National Oceanic and Atmospheric Administration, 1998). There are two major rivers that discharge into Barnegat Bay: the Metedeconk River in the north part of the estuary and Toms River in the north-central part (fig. 1). The estuary has only three inlets connecting it to the Atlantic Ocean: Point Pleasant Canal via the Manasquan Inlet in the north, Little Egg Inlet in the south, and Barnegat Inlet almost equidistant between them (fig. 1).
In cooperation with the New Jersey Department of Environmental Protection (NJDEP), the U.S. Geological Survey (USGS) began a multidisciplinary research project in 2011 to improve understanding of the physical factors that influence water quality in the Barnegat Bay estuary. The team was composed of staff from three USGS science centers. Scientists collected information on the magnitude and direction of tidal currents, suspended sediment concentrations, and fluxes of dissolved nutrients, modeled the movement of water and sediments in the estuary, and mapped the sea floor of Barnegat Bay by using a suite of geophysical tools. A swath bathymetric sonar provided measurements of sea-floor depth; a sidescan sonar provided information about the acoustic properties of sediment on the sea floor; a subbottom profiler provided imaging of sediment layers beneath the floor of the estuary; and surficial sea-floor sediment samples, photographs, and video were used to validate the acoustic data. The methods used to collect and process these data are described in this report.

The physical dimensions of Barnegat Bay that might influence spatial variations in water quality also resulted in a challenging environment for geophysical surveys. Only 40 percent of the estuary is deeper than $1.5 \mathrm{~m}$ and could be accessed by using vessel-based acoustic mapping techniques. Water depths less than $1.5 \mathrm{~m}$ were mapped separately by using optical techniques (Wright and others, 2014). Because of the size and shallow depths of the bay, the sea floor was mapped and sediments were sampled over four surveys between November 2011 and September 2013 (fig. 2; table 1). In total, approximately $100 \mathrm{~km}^{2}$ area was covered by using acoustic, vessel-based techniques.

\section{Data Collection and Processing}

\section{Survey Operations}

The project goal was to collect bathymetric, backscatter, seismic-reflection profile, and ground validation data (through collection of samples, photographs and videos) in areas of the bay deeper than $1.5 \mathrm{~m}$ to produce a broad regional understanding of the morphology and geology of the estuary. 


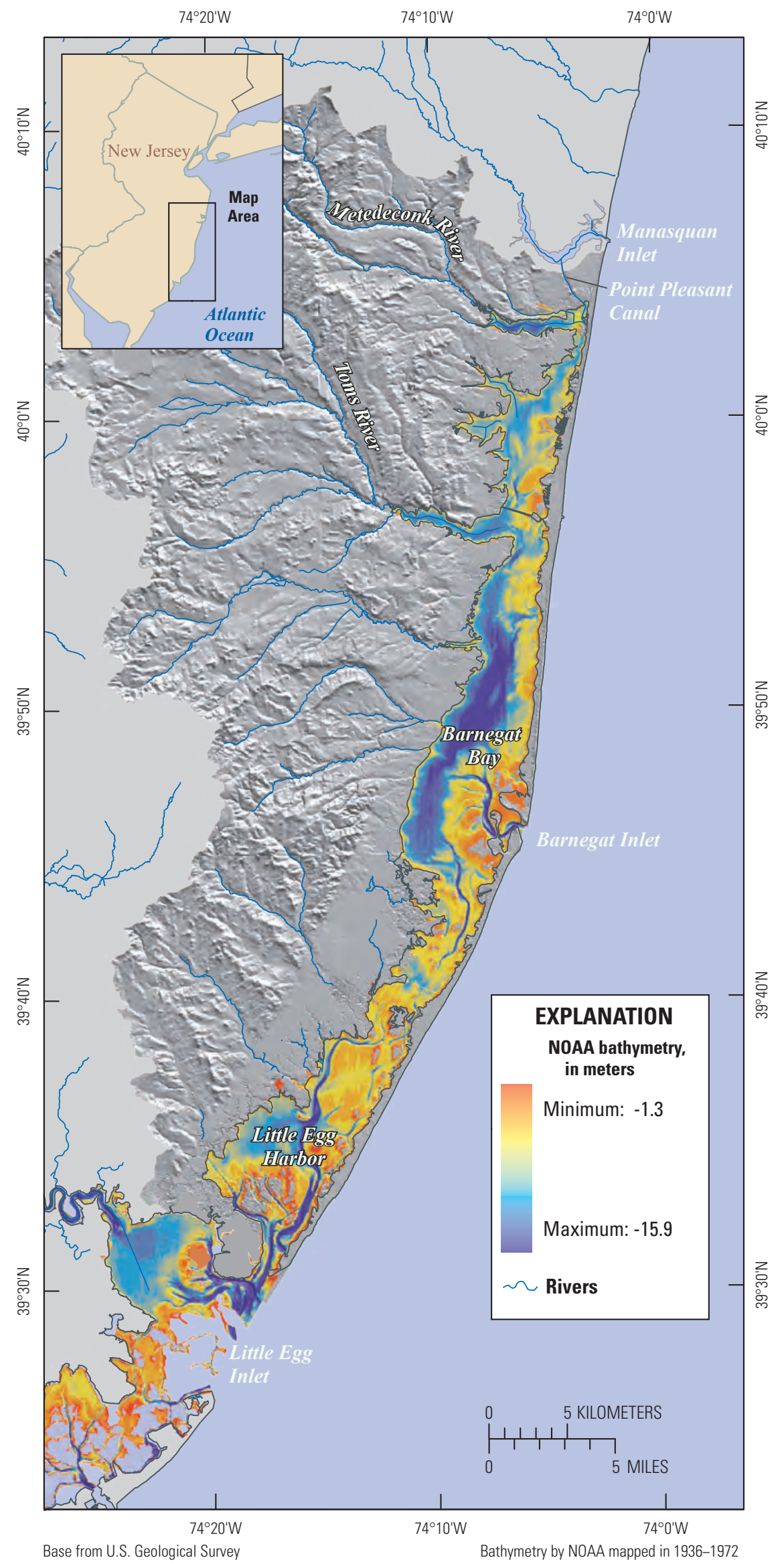

Figure 1. The watershed, regional bathymetry, and three inlets in Barnegat Bay, New Jersey. Data are from the U.S. Geological Survey and the National Oceanic and Atmospheric Administration (NOAA). 


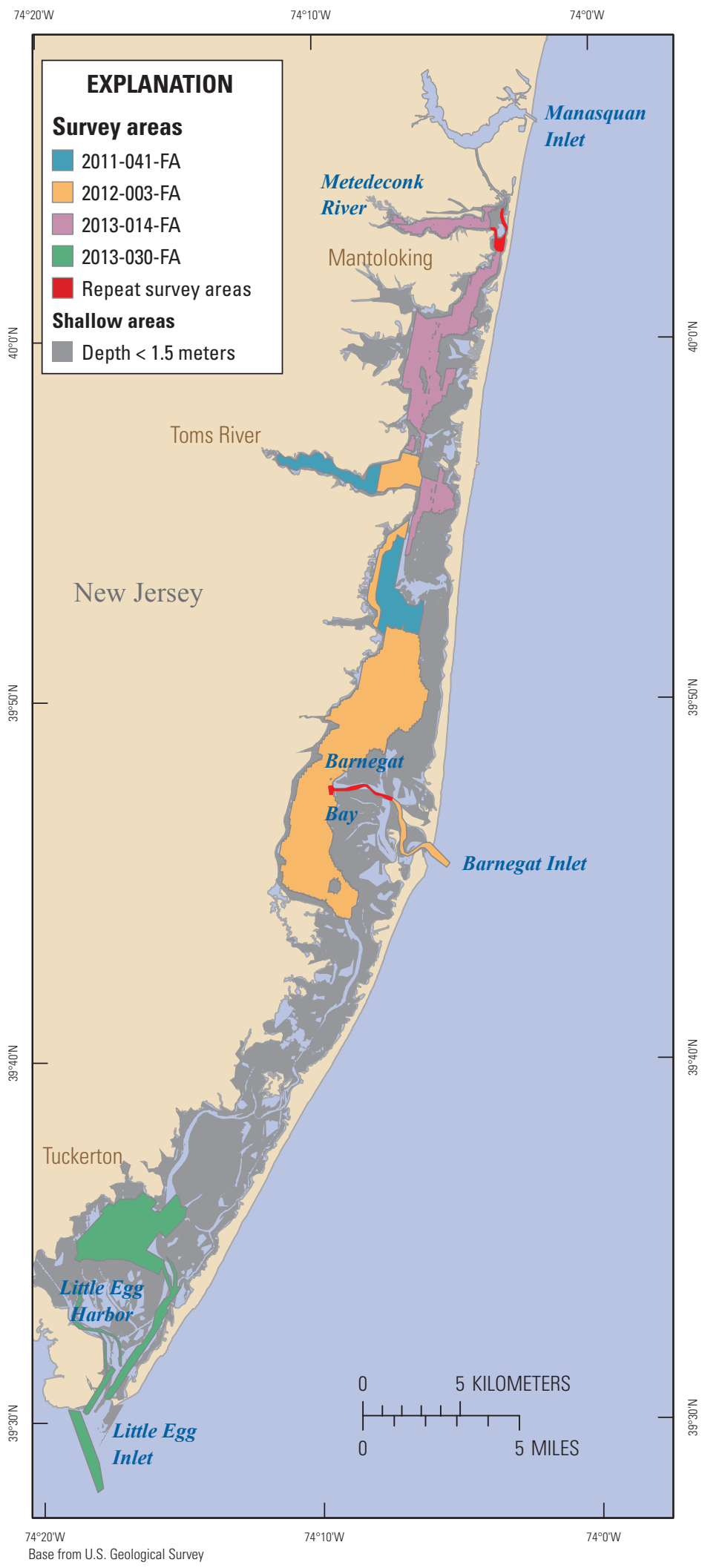

Figure 2. Areas covered by the four surveys conducted in Barnegat Bay, New Jersey, by the U.S. Geological Survey (USGS) between 2011 and 2013. Small areas covered in both 2011 and 2013 are shown in red. Data are from the USGS. 
Table 1. Details of the four geophysical surveys conducted by the U.S. Geological Survey in Barnegat Bay, New Jersey, between 2011 and 2013.

[Ground validation data include bottom photographs, bottom video, and sediment samples. SEABOSS, SEABed Observation and Sampling System; --, no data]

\begin{tabular}{cllcllc}
\hline \multirow{2}{*}{ Survey } & \multirow{2}{*}{ Start date } & \multirow{2}{*}{ End date } & \multicolumn{3}{c}{ Data collected } \\
\cline { 4 - 7 } & & & Bathymetry backscatter & Backscatter & Seismic-reflection profile & Ground validation \\
\hline $2011-041-F A$ & $10 / 31 / 2011$ & $11 / 7 / 2011$ & SWATHplus-H & Klein 3000 & EdgeTech 424 & -- \\
$2012-003-F A$ & $3 / 20 / 2012$ & $4 / 8 / 2012$ & SWATHplus-H & EdgeTech 4200 & EdgeTech 424 & SEABOSS \\
$2013-014-F A$ & $3 / 13 / 2013$ & $3 / 29 / 2013$ & SWATHplus-H & EdgeTech 4200 & EdgeTech 424 & SEABOSS \\
2013-030-FA & $9 / 11 / 2013$ & $9 / 18 / 2013$ & SWATHplus-H & EdgeTech 4200 & EdgeTech 424 & SEABOSS \\
\hline
\end{tabular}

The survey areas were defined as areas of the bay deeper than $1.5 \mathrm{~m}$ according to soundings collected by the National Oceanic and Atmospheric Administration between 1934 and 1936; these soundings were the only existing bathymetry of the estuary prior to this study (National Oceanic and Atmospheric Administration, 1998; fig. 1).

Surveys were conducted aboard the research vessel (RV) Rafael during daylight operations in the spring and fall (fig. 3), when recreational vessel traffic is minimal and the water column is most suitable for acoustic surveys. A survey line spacing of $50 \mathrm{~m}$ between adjacent lines produced seamless (100-percent) sidescan coverage and bathymetric data with gaps (50 percent) between lines of 25 to $30 \mathrm{~m}$, depending on water depth. During survey 2013-030-FA in Little Egg Harbor, the survey line spacing was increased to $75 \mathrm{~m}$ between survey lines to cover a greater extent of the harbor in a short time frame. This survey approach of 100-percent sidescansonar coverage and 50-percent bathymetric coverage produced a high-resolution (10-m), continuous regional terrain model without gaps between lines. Tie lines, or those lines oblique to

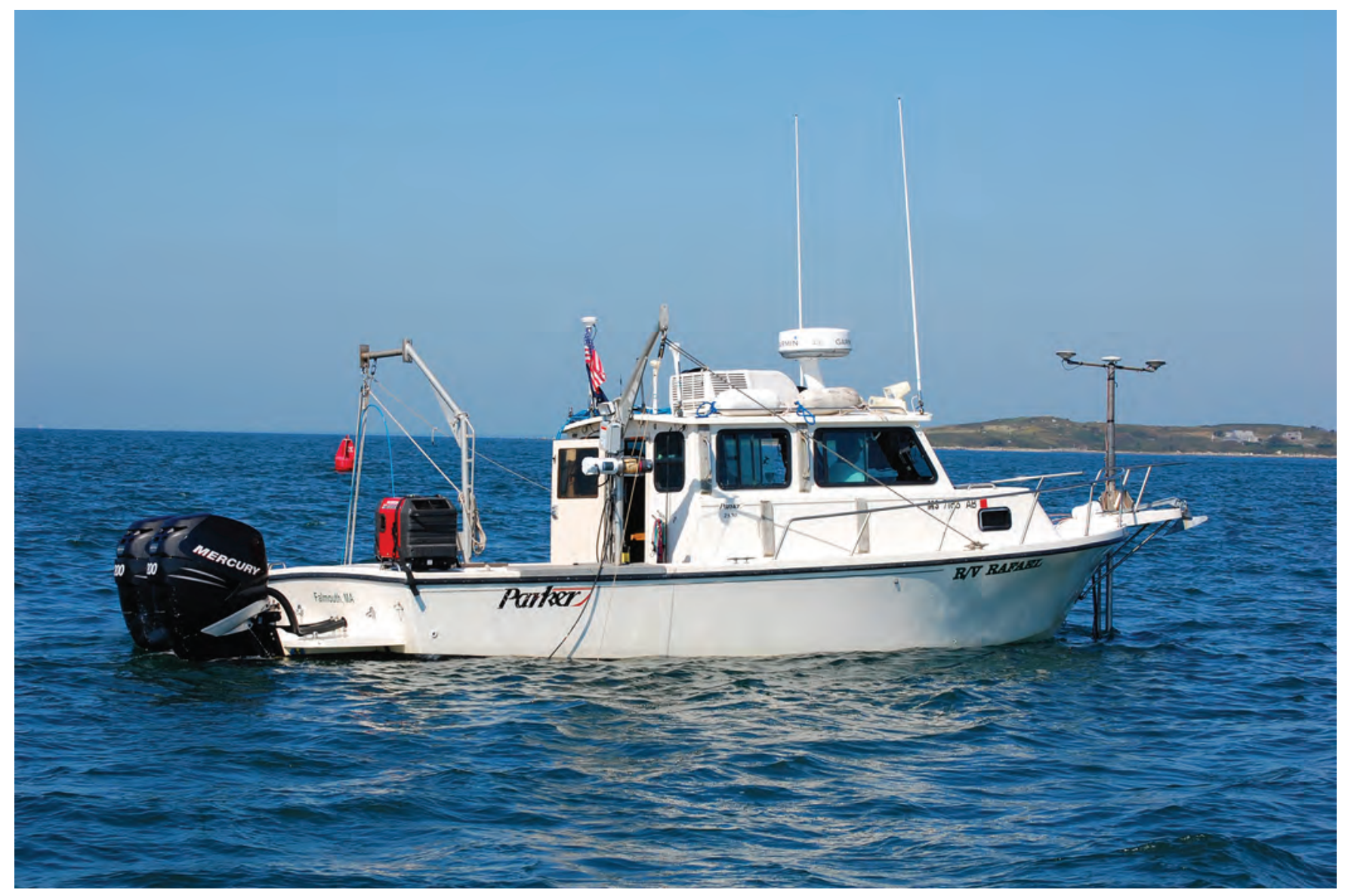

Figure 3. The research vessel (RV) Rafael showing the SWATHplus-H bathymetric sonar mounted on the bow. The sonar head is 0.7 meters below the waterline when deployed during data collection. Photograph by David Foster, U.S. Geological Survey. 
evenly spaced tracklines, were collected during each survey for quality control and to aid in seismic-stratigraphic correlation and interpretation (fig. 4).

A second survey, initially planned for early November 2012, was postponed until spring 2013 because of the landfall of Hurricane Sandy on the New Jersey coast on October 29,2012 . Two areas from the original 2011 survey area were occupied in 2013 (see red areas in fig. 2) to assess any measurable bathymetric change produced from Hurricane Sandy.

\section{Bathymetry}

Bathymetric data were collected by using a SWATHplus-H interferometric sonar, operating at a frequency of 468 kilohertz $(\mathrm{kHz})$ and covering a distance of 2,166 km of linear tracklines throughout Barnegat Bay. The sonar transducers were mounted on a rigid pole from the bow of the RV Rafael, about $0.7 \mathrm{~m}$ below the waterline (fig. 3).

A CodaOctopus motion reference unit was mounted directly above the sonar transducers and continuously measured vertical displacement (heave) and attitude (pitch and roll) of the vessel during data acquisition. Vertical offsets between navigation and attitude antennas and the SWATHplus-H transducers were applied during acquisition in the configuration files for the SWATHplus and Coda Octopus software. Sound velocity profiles were collected approximately every two hours, or when refraction was noted in acquisition software, by using a hand deployed sampler. An AML Oceanographic SVP Plus profiler was used during surveys 2011-041-FA and 2012-003-FA, and an AML Oceanographic MINOS-X profiler was used during 2013-014 and 2013-030.

CARIS Hydrographic Information Processing System (HIPS) was used to process and edit the bathymetric line files, correct for changes in speed of sound, apply tide corrections, and remove erroneous points. The bathymetric data were collected and referenced to the North American Vertical Datum of 1988 (NAVD 88) to facilitate merging with lidar elevation data and circulation modeling.

\section{Terrain Model}

Because the bay is shallow, collecting 100-percent bathymetric coverage of the bay would have been prohibitively expensive and time consuming. Instead, bathymetric data were collected with the purpose of building a continuous terrain model that would fill in the gaps between adjacent survey lines. The bathymetric data were edited to remove soundings that exceeded three to four times the nadir depth. This filter trimmed the far range of the swath width to retain high-quality soundings where refraction artifacts were minimal (fig. $5 A$ ). A Triangulated Irregular Network (TIN) model was used to create a continuous surface without gaps between lines from the input points (figs. $5 B$ and $C$ ). The TIN was then converted to a $10-\mathrm{m}$ resolution grid by using the natural neighbors method of interpolation (fig. 5D) and is included in the Data Catalog along with the original bathymetric grid and metadata.

\section{Backscatter}

Backscatter data were collected along approximately 2,010 km of tracklines and provided 100-percent coverage of the sea floor, producing a continuous mosaic of acoustic backscatter covering approximately $100 \mathrm{~km}^{2}$. Three different sonars were used to collect and produce the backscatter mosaics. During USGS Survey 2011-041-FA, a Klein 3000 sidescan sonar operating at dual frequencies of 132 and $445 \mathrm{kHz}$ was used (fig. $6 \mathrm{~A}$, table 1). During the remaining three surveys (2012-003-FA, 2013-014-FA, and 2013-030FA), backscatter data were collected by using an EdgeTech 4200 operating at dual frequencies of 100 and $400 \mathrm{kHz}$ (fig. $6 B$ ). The Klein and EdgeTech sonars were towed from the port side of the RV Rafael approximately $1.5 \mathrm{~m}$ astern. Coregistered backscatter data were also collected with the SWATHplus-H interferometric sonar during all four surveys; however, SWATHplus-H backscatter data were only processed during parts of 2012-003-FA in Barnegat Inlet and 2013030-FA in Little Egg Inlet (fig. 4). Because of the variable trackline orientation in these two areas, the pole-mounted sonar produced better results than the towed sidescan sonar. Backscatter files were recorded to XTF and JSF formats and processed by using Xsonar, SonarWiz, and PCI Geomatica. Complete processing details are recorded in the metadata.

Two areas of overlapping backscatter coverage exist (red areas in fig. 2). In Mantoloking, New Jersey, the EdgeTech backscatter was used in the final mosaic, despite being collected after Hurricane Sandy, because its quality was more suitable for sediment characterization than that of the Klein 3000 data.

\section{Seismic-Reflection Profiling}

Seismic-reflection profile data were collected along approximately 2,092 km of survey lines by using an EdgeTech 424 subbottom-profiling system, which was towed from the starboard side of the RV Rafael (fig. 7). SonarWiz seismic-acquisition software was used to control the EdgeTech 3100 portable topside unit. Navigation was supplied by a Differential Global Positioning System receiver with a Hemisphere antenna located on the portside aft cabin. Data were processed by using Seismic Unix and SIOSEIS software to produce profiles of the final processed trace data, which are included in this report as 8-bit, grayscale, variable-density plots in Portable Network Graphics (PNG) format. The final shot-point and trackline navigation are available in the Data Catalog. Additional details about the acquisition and processing of seismic-reflection data can be found in the metadata for the trackline and shot-point spatial datasets and in the metadata for the PNG profile images in the Data Catalog. 


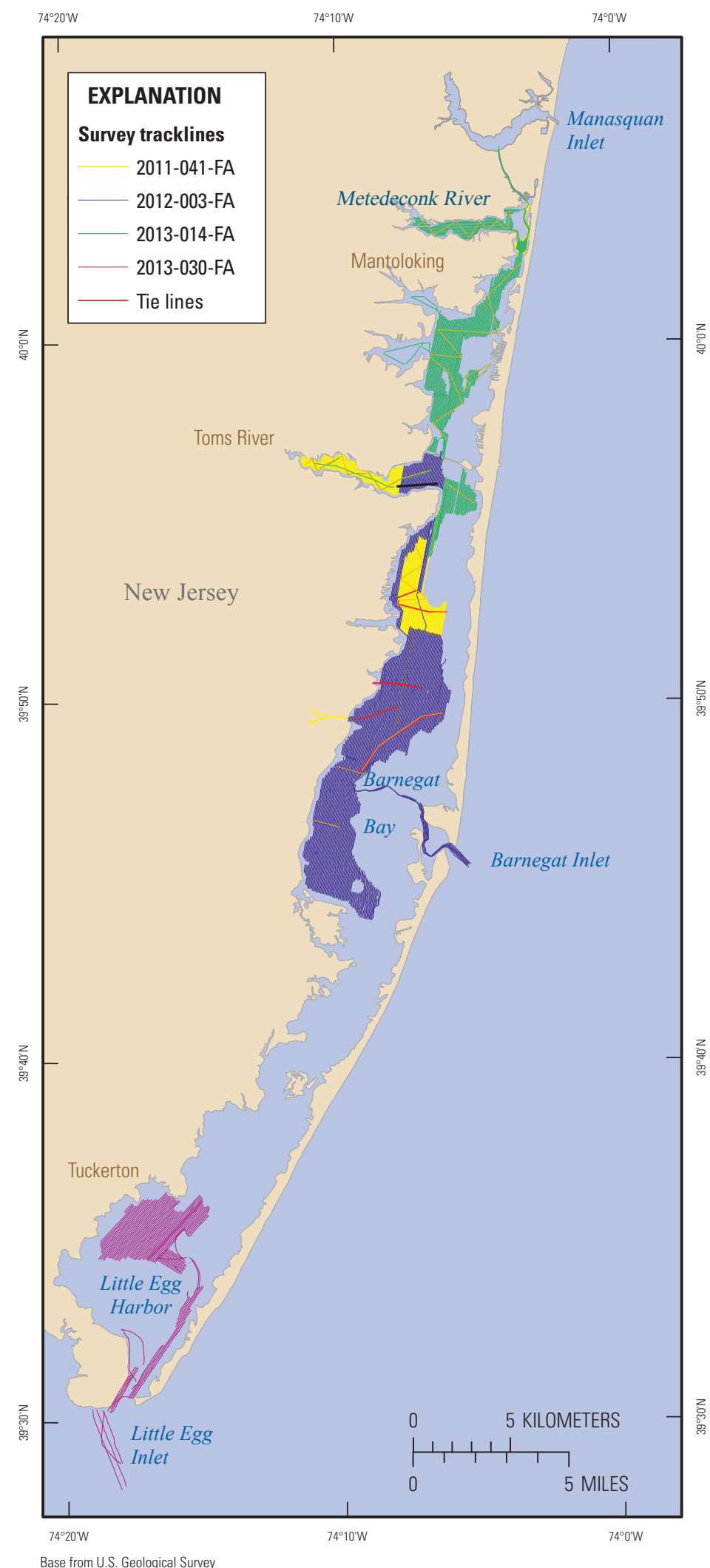

Figure 4. Bathymetric tracklines and tie lines collected in Barnegat Bay, New Jersey, by the U.S. Geological Survey (USGS) between 2011 and 2013. Data are from the USGS. 

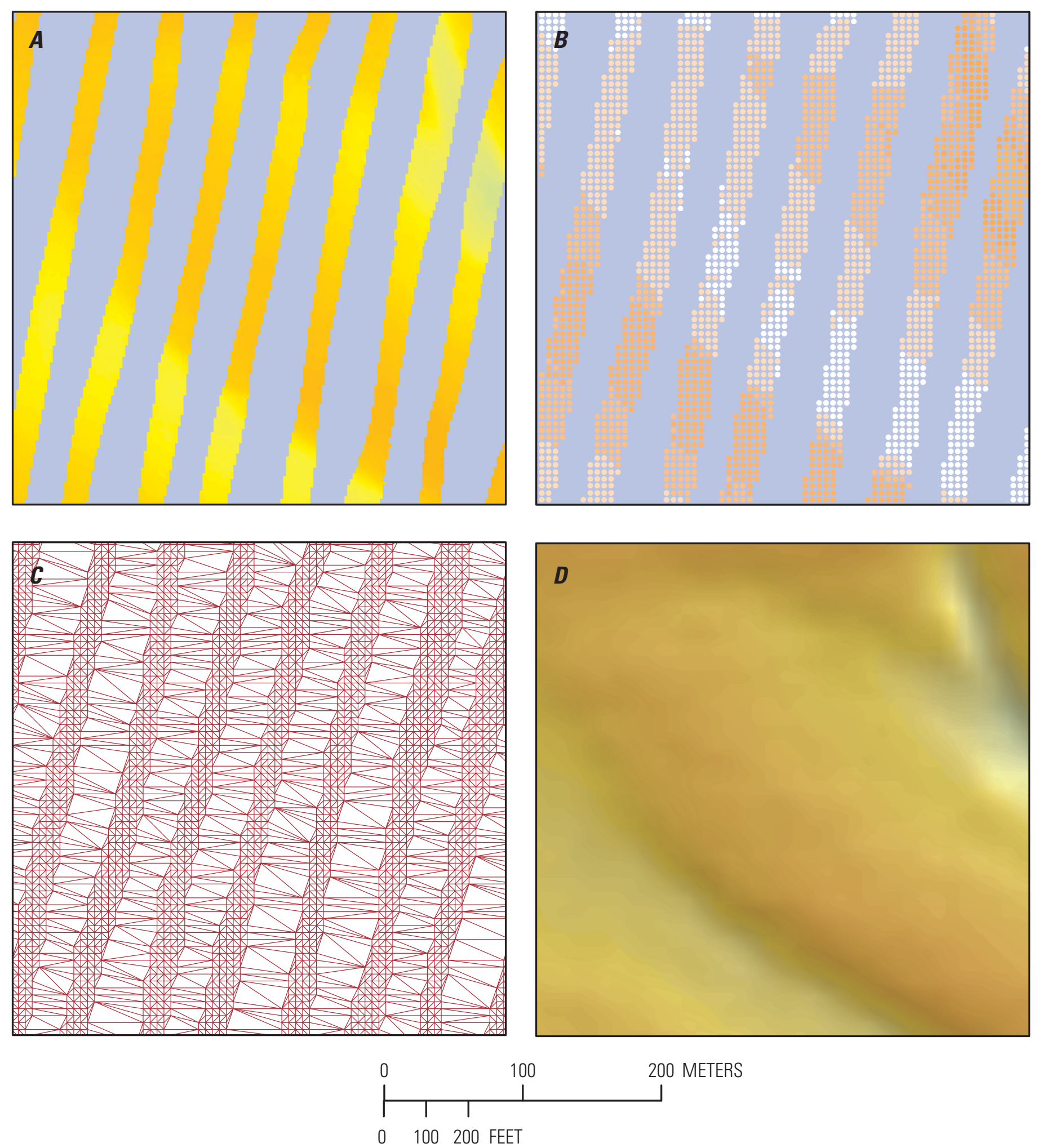

Figure 5. Process of converting bathymetric trackline data with gaps between adjacent lines to a continuous terrain model. $A$, Final edited bathymetric data with gaps between adjacent lines. $B$, Raster data converted to $x, y, z$ point data. $C$, Triangulated irregular network (TIN) produced from input $x, y, z$ points showing the edges of each face in the TIN. $D$, Final 10-meter grid created from the terrain model without gaps between survey lines. 


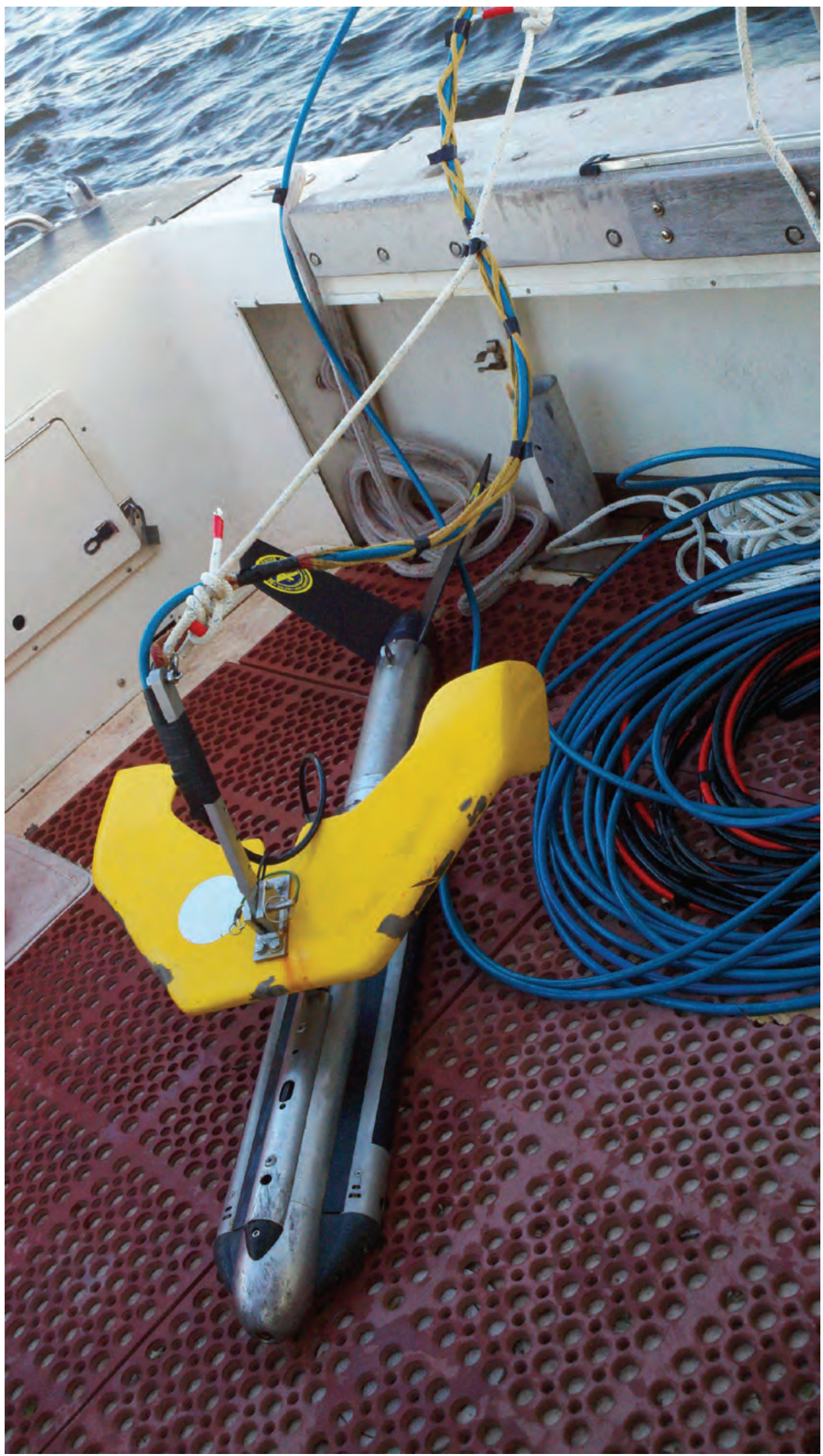

Figure 6. A, The Klein 3000 sidescan-sonar towfish used during survey 2011-041-FA and $B$, the EdgeTech 4200 sidescan sonar towfish used during surveys (2012-003-FA, 2013-014-FA, and 2013-030-FA). Photographs by Jennifer Miselis, U.S. Geological Survey. 
B

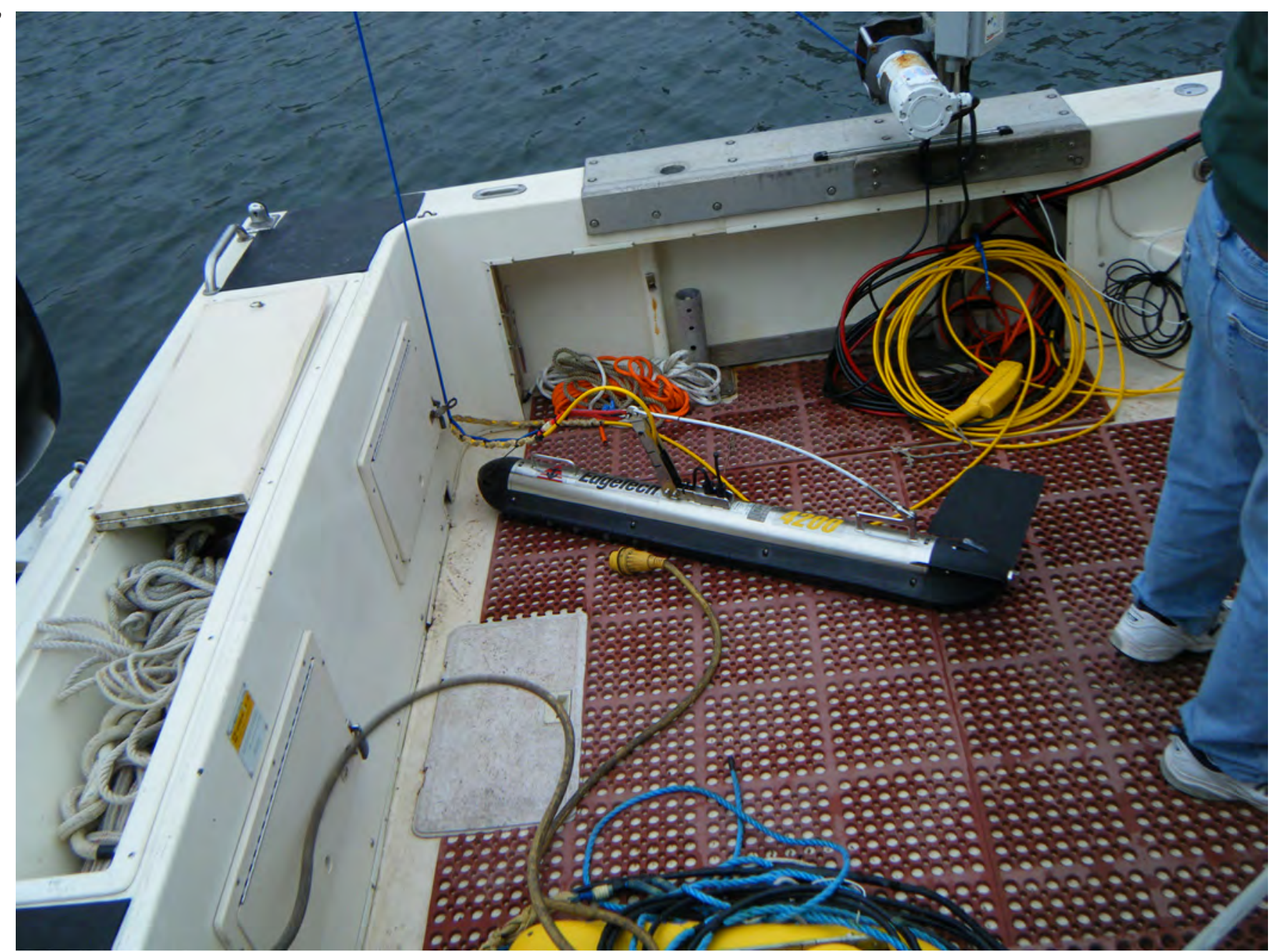

Figure 6. A, The Klein 3000 sidescan-sonar towfish used during survey 2011-041-FA and $B$, the EdgeTech 4200 sidescan sonar towfish used during surveys (2012-003-FA, 2013-014-FA, and 2013-030-FA). Photographs by Jennifer Miselis, U.S. Geological Survey.-Continued 


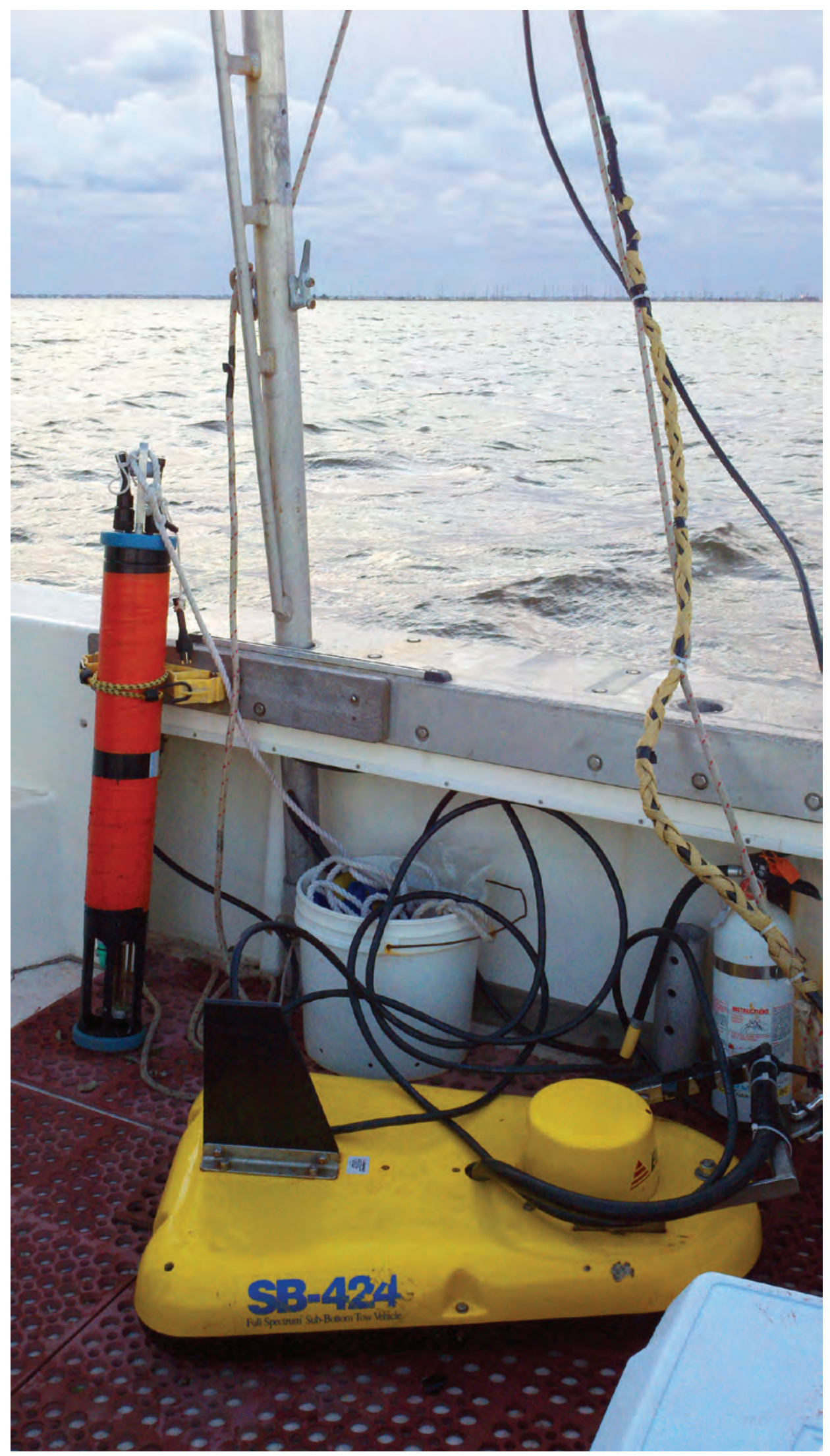

Figure 7. The EdgeTech 424 subbottom-profiling towfish and the davit used when deployed from the starboard side of the research vessel Rafael. Photograph by Jennifer Miselis, U.S. Geological Survey. 


\section{Ground Validation}

The geophysical data from sonars were verified with bottom photographs, bottom video, and sediment samples collected by using the USGS SEABed Observation and Sampling System (SEABOSS; fig. 8) deployed from the RV Rafael. Three SEABOSS deployments at the end of surveys 2012-030-FA, 2013-014-FA, and 2013-030-FA occupied 186 target stations and collected 594 bottom photographs, 186 sediment samples, and approximately $4.6 \mathrm{~km}$ of bottom video tracklines (fig. 9).

Backscatter, seismic profile, and bathymetric data were used to identify target locations for sediment sampling and photography. At each target station, the survey vessel was positioned windward of the target location so that after the SEABOSS sampler was deployed the vessel and sampler would drift with wind and current over the target location or along a desired transect. During the drift, continuous video was recorded and bottom photographs were acquired at select locations along the drift transect by the use of a handtriggered shutter while the real-time bottom video was viewed. Sediment samples were acquired at the end of each transect by landing the sampler firmly on the bottom and engaging the Van Veen sampler. The SEABOSS sampler was then hoisted to the starboard rail of the RV Rafael, the surface of the recovered sediment was subsampled by using a 2-centimeter scoop, and samples were stored in bags for analysis. The Data Catalog includes the following data collected with SEABOSS:

1. The location and laboratory analysis of the 186 sediment samples in shapefile format

2. The location (shapefile) and images (.jpg) of the 594 bottom photographs

downloads

raster-all ZIP files listed in table 3

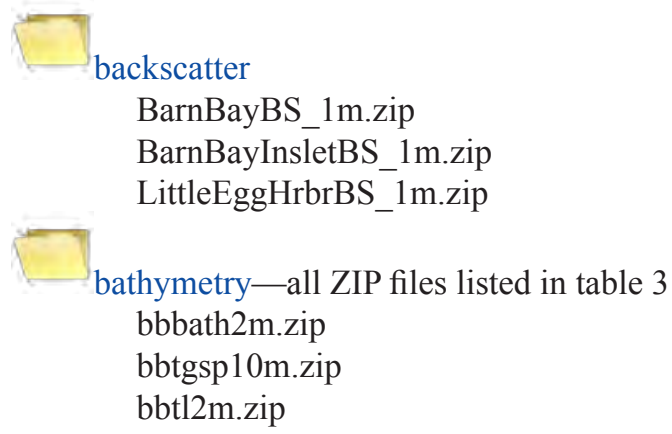

hyperlink images_-all ZIP files listed in table 4. This folder has two subdirectories that contain folders for each survey.

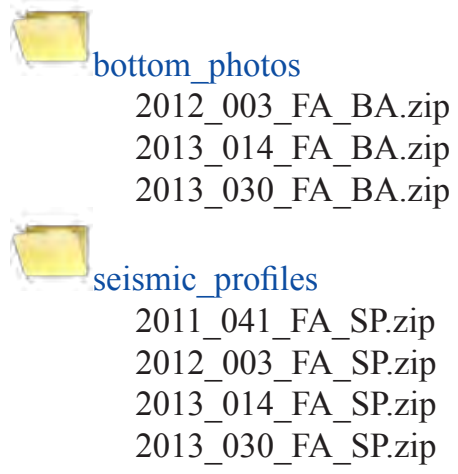

3. The tracklines (shapefile) along which continuous video was acquired

\section{Data Catalog}

The data described in this report are available as separate compressed ZIP files in the directory structure described below. The ZIP files contain spatial data that can be viewed in Esri geographic information system (GIS) software or other software that can read Esri grids and shapefile formats. Users should replicate this folder structure on a local hard drive to ensure that the hyperlink pathways in the downloads/shapefile/ BarnBayBotPhotos.shp and BarnBaySeisTrks.shp files will work. 


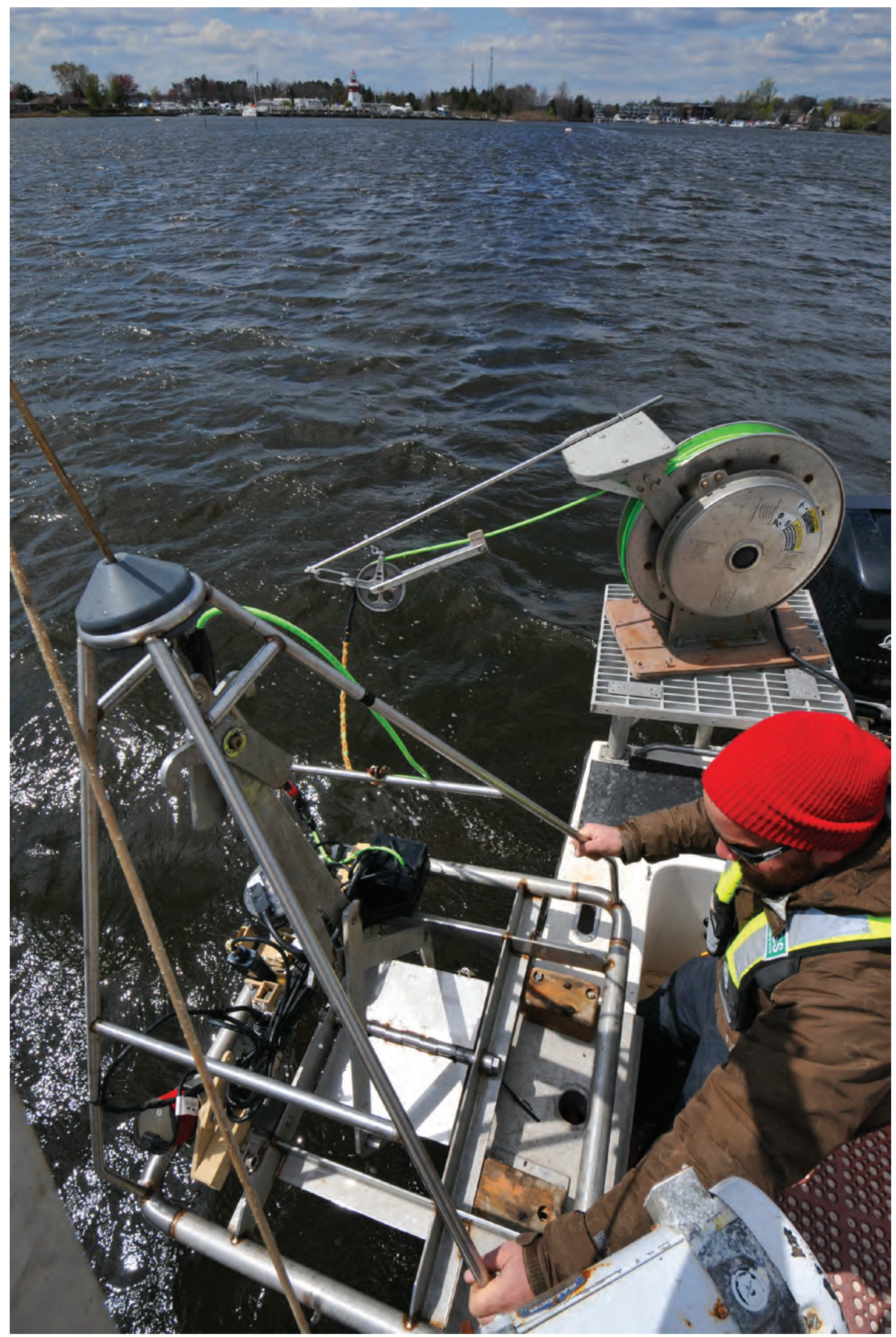

Figure 8. The SEABed Observation and Sampling System deployed from the research vessel (RV) Rafael. Photograph by Dann Blackwood, U.S. Geological Survey. 


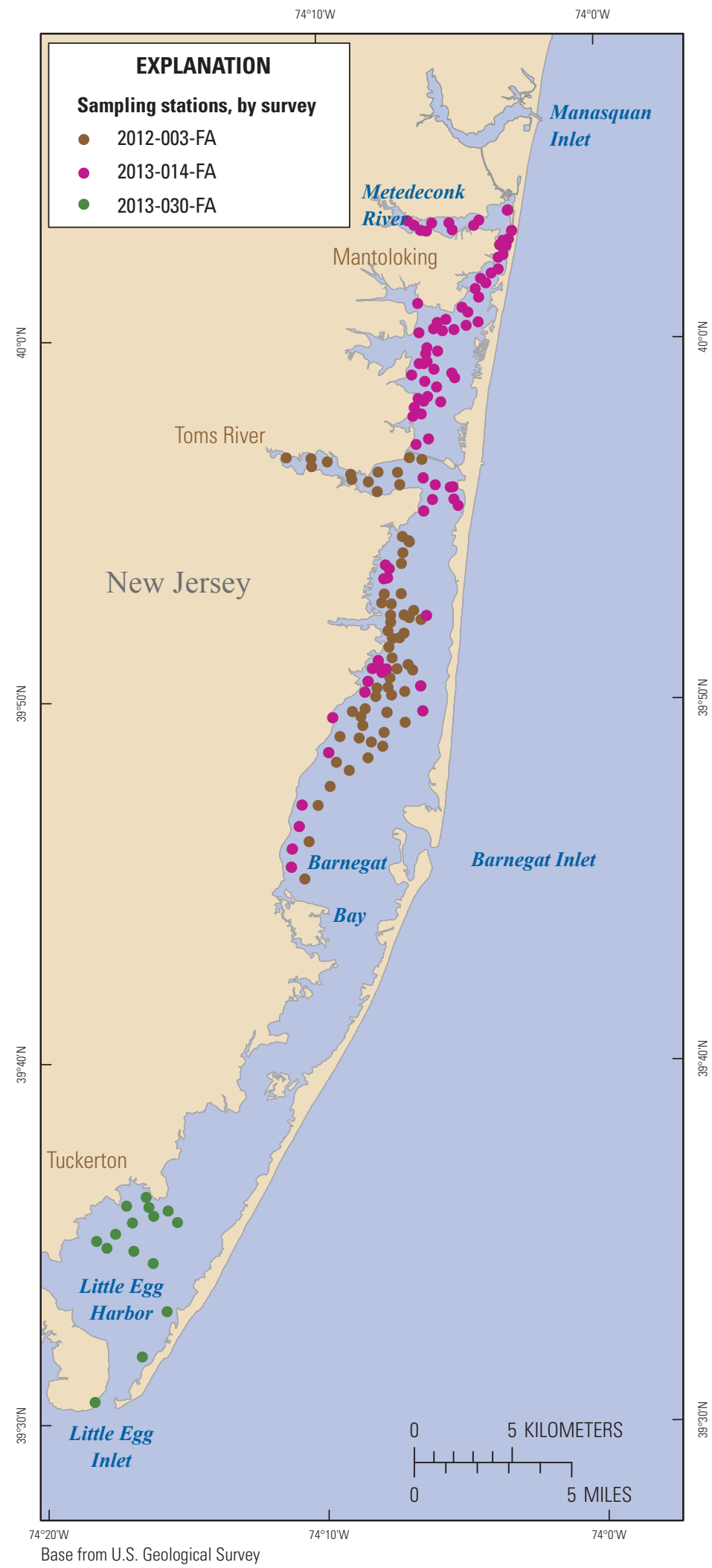

Figure 9. The 186 target SEABed Observation and Sampling System sampling stations in areas surveyed by the U.S. Geological Survey (USGS) in Barnegat Bay, New Jersey, from 2011 to 2013. Data are from the USGS. 


\section{Marine Geophysical Data Collected in a Shallow Back-Barrier Estuary, Barnegat Bay, New Jersey}

Table 2. List of vector data published in this report in the shapefile directory.

[SEABOSS, SEABed Observation and Sampling System]

\begin{tabular}{lll}
\multicolumn{1}{c}{ Layer } & \multicolumn{1}{c}{ Description } & \multicolumn{1}{c}{ Download } \\
\hline BarnBayBathTrks.shp & Survey tracklines for bathymetric data & BarnBayBathTrks.zip \\
BarnBayBSTrks.shp & Survey tracklines for backscatter data & BarnBayBSTrks.zip \\
BarnBaySeisTrks.shp & Survey tracklines for seismic profile data & BarnBaySeisTrks.zip \\
BarnBaySeisShot_100.shp & Seismic shot navigation data at 500-shot intervals & BarnBaySeisShot100.zip \\
BarnBaySedSamples.txt & Sediment sample locations with grain size results & BarnBaySedSamples.zip \\
BarnBayBotPhotos.shp & Locations of bottom photographs collected from the SEABOSS & BarnBayBotPhotos.zip \\
BarnBaySEABOSSTrks.shp & Survey tracklines for bottom video & BarnBaySEABOSSTrks.zip \\
\hline
\end{tabular}

Table 3. List of bathymetric and backscatter data in the directories downloads/raster/bathymetry/ and downloads/raster/backscatter/.

\begin{tabular}{|c|c|c|}
\hline Layer & Description & Download \\
\hline \multicolumn{3}{|c|}{ downloads/raster/bathymetry } \\
\hline bbbath $2 \mathrm{~m}$ & 2-meter gridded bathymetry Esri 32-bit & $\begin{array}{l}\text { bbbath2m.zip } \\
2.0 \mathrm{Mb}\end{array}$ \\
\hline bbtl $2 \mathrm{~m}$ & 2-meter gridded bathymetry (tie lines) Esri 32-bit & $\begin{array}{l}\text { bbtl2m.zip } \\
1.05 \mathrm{Mb}\end{array}$ \\
\hline bbtgsp $10 \mathrm{~m}$ & 10-meter gridded bathymetry Esri 32-bit & $\begin{array}{l}\text { bbtgsp } 10 \mathrm{~m} . z i p \\
3.6 \mathrm{Mb}\end{array}$ \\
\hline \multicolumn{3}{|c|}{ downloads/raster/backscatter } \\
\hline BarnBayBS_1m.tif & 1-meter backscatter mosaic Barnegat Bay 8-bit & $\begin{array}{l}\text { BarnBayBS_1m.zip } \\
53 \mathrm{Mb}\end{array}$ \\
\hline BarnBayInletsBS_1m.tif & 1-meter backscatter mosaic Barnegat Bay 8-bit & $\begin{array}{l}\text { BarnBayInletsBS_1m.zip } \\
5.4 \mathrm{Mb}\end{array}$ \\
\hline LittleEggHbrBS_1m.tif & 1-meter backscatter mosaic Barnegat Bay 8-bit & $\begin{array}{l}\text { LittleEggHbrBS_1m.zip } \\
\text { 9.5 Mb }\end{array}$ \\
\hline
\end{tabular}


Table 4. Bottom photographs and seismic profile images in the directories downloads/ hyperlink_images/bottom_photos/and downloads/hyperlink_images/seismic_profiles/.

[JPEG, Joint Photographic Experts Group; PNG, Portable Network Graphics]

\begin{tabular}{|c|c|c|}
\hline Folder & Description & Download \\
\hline \multicolumn{3}{|c|}{ downloads/hyperlink_images/bottom_photos/ } \\
\hline 2012_003_FA & Bottom photographs in JPEG format & $\begin{array}{l}2012 \text { _003_FA_BP.zip } \\
540 \mathrm{Mb}\end{array}$ \\
\hline 2013_014_FA & Bottom photographs in JPEG format & $\begin{array}{l}2013 \text { _014_FA_BP.zip } \\
453 \mathrm{Mb}\end{array}$ \\
\hline 2013_030_FA & Bottom photographs in JPEG format & $\begin{array}{l}2012 \_030 \text { FA_BP.zip } \\
52 \mathrm{Mb}\end{array}$ \\
\hline \multicolumn{3}{|c|}{ downloads/hyperlink_images/seismic_profiles/ } \\
\hline 2011_041_FA & Seismic profile images in PNG format & $\begin{array}{l}2011 \text { 041_FA_SP.zip } \\
109 \mathrm{Mb}\end{array}$ \\
\hline 2012_003_FA & Seismic profile images in PNG format & $\begin{array}{l}2012 \text { _003_FA_SP.zip } \\
423 \mathrm{MB}\end{array}$ \\
\hline 2013_014_FA & Seismic profile images in PNG format & $\begin{array}{l}2013 \text { _014_FA_SP.zip } \\
254 \mathrm{Mb}\end{array}$ \\
\hline 2013_030_FA & Seismic profile images in PNG format & $\begin{array}{l}2013 \text { _030_FA_SP.zip } \\
198 \mathrm{Mb}\end{array}$ \\
\hline
\end{tabular}

Vector Data.-The vector data (table 2; survey tracklines, seismic shot navigation, and locations of samples, photographs, and video) are delivered in Esri shapefile format using the Geographic Coordinate System. The link in the "Download" column provides access to the compressed ZIP file containing the data in shapefile format.

Raster Data.-The raster data are divided into two formats, georeferenced (bathymetry and backscatter) in table 3 and non-georeferenced (seismic profiles and bottom photographs) in table 4.

\section{Acknowledgments}

We thank the following (USGS) personnel for their contributions to this report: Anthony Navoy and Robert Nicholson provided logistical support prior to survey operations; Eric Moore, David Foster, Aaron Turecek, and William Pfeiffer participated in three surveys; Elizabeth Pendleton and Laura Brothers provided helpful technical reviews, and Jonas CaseyWilliams provided a helpful editorial review. VeeAnn Cross provided a detailed review of the metadata, and Andrea Toran guided this report through the publishing process.

\section{References Cited}

National Oceanic and Atmospheric Administration, 1998, Estuarine bathymetric digital elevation models (30 meter resolution) derived from source hydrographic survey soundings collected by NOAA: National Oceanic and Atmospheric Administration, National Ocean Service, Special Projects, accessed October 27, 2011, at http://estuarinebathymetry.noaa.gov/bathy_htmls/M070. html and http://estuarinebathymetry.noaa.gov/bathy_htmls/ M080.html.

Wright, C.W., Troche, R.J., Klipp, E.S., Kranenburg, C.J., Fredericks, Xan, and Nagle, D.B., 2014, EAARL-B submerged topography - Barnegat Bay, New Jersey, preHurricane Sandy, 2012: U.S. Geological Survey Data Series 885, http://dx.doi.org/10.3133/ds885. 

For more information concerning this report, contact:

Director, Woods Hole Coastal and Marine

Science Center

U.S. Geological Survey

384 Woods Hole Road

Quissett Campus

Woods Hole, MA 02543-1598

WHSC_science_director@usgs.gov

508-548-8700 or 508-457-2200

or visit our Web site at:

http://woodshole.er.usgs.gov/

Publishing support by:

The Pembroke Publishing Service Center. 


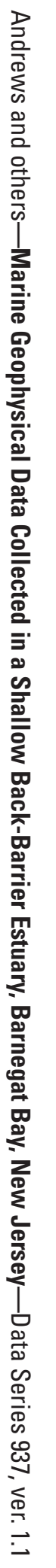

